Available online at http://jurnal.goretanpena.com/index.php/JSSR

\title{
RANCANG BANGUN APLIKASI VISUAL BASIC DALAM PERHITUNGAN ANGKA INDEKS RELATIF
}

\author{
Zuhri \\ Sekolah Tinggi Ilmu Manajemen Sukma, Medan \\ e-mail: Zuhrimuin63@gmail.com
}

\begin{abstract}
Every year the price and consumption of rice in Indonesia fluctuates. Likewise, there are fluctuations in the rupiah exchange rate against the dollar. Index numbers are an easy way to find comparisons from time to time whether there is an increase or decrease. The index number is used to determine the percentage increase or decrease in a value at a certain time with a value at another time that is set as the base time. In order to be flexible in the calculation and flexible in data changes, a desktop-based application was built using the programming language from Visual Basic software and the database from Microsoft Access. The results of the calculation of the index figure for the Rupiah Exchange Rate against the Dollar, on February 11, 2021 there was a decrease of 7\% compared to February 10, 2021. Likewise, the price of rice in 2019 there was an increase of $0.31 \%$ compared to 2018, while rice consumption in 2019 there was a decrease $3 \%$ compared to 2018
\end{abstract}

Keywords: Index Numbers, Microsoft Access, Visual Basic.

\begin{abstract}
Abstrak: Setiap tahun harga dan konsumsi beras di Indonesia mengalami fluktuasi. Demikian juga fluktuasi terdapat pada kurs rupiah terhadap dolar. Angka Indeks merupakan cara yang mudah dalam mencari perbadingan dari waktu ke waktu apakah terdapat peningkatan ataupun penuruan. Angka indeks tersebut digunakan untuk mengetahui persentasi kenaikan ataupun penurunan dari suatu nilai pada waktu tertentu dengan nilai di waktu lain yang ditetapkan sebagai waktu dasar. Agar fleksibelnya perhitungan tersebut dan fleksibelnya perubahan data maka dibangunlah sebuah aplikasi yang berbasis desktop dengan menggunakan bahasa pemrograman dari software Visual Basic dan databasenya dari Microsoft Access. Hasil perhitungan angka indeks untuk Kurs Rupiah terhadap Dolar, pada tanggal 11 Februari 2021 terdapat penurunan 7\% dibandingkan tanggal 10 Februari 2021. Demikian juga harga beras pada tahun 2019 terdapat kenaikan $0,31 \%$ dibandingkan tahun 2018, sedangkan konsumsi beras pada tahun 2019 terdapat penurunan 3\% dibandingkan tahun 2018.
\end{abstract}

Kata kunci: Angka Indek, Microsoft Access, Visual Basic.

\section{PENDAHULUAN}

Dalam ilmu statistik terdapat metode untuk membandingkan suatu nilai dari waktu tertentu dengan nilai yang lain. Hasil perbandingan tersebut disebut dengan Angka Indeks. Angka Indeks merupakan angka perbandingan yang dinyatakan dalam persentase untuk mengukur perubahan relatif satu variabel atau lebih pada waktu tertentu atau tempat tertentu, dibandingkan dengan variabel yang sama pada waktu atau tempat yang lainnya. Hasil perbandingan digunakan untuk mengukur perubahan variabel yang dinyatakan dalam persentase. Angka indeks digunakan untuk mengetahui perubahan-perubahan variabel yang berkaitan dengan banyak aspek kehidupan manusia.

Komputer merupakan alat bantu yang dapat digunakan untuk memudahkan proses perhitungan, termasuk juga dalam menghitung angka indeks. Melalui komputer, dapat dibuat aplikasi yang Dalam ilmu statistik terdapat metode untuk membandingkan suatu nilai dari waktu tertentu dengan nilai yang lain. 
Available online at http://jurnal.goretanpena.com/index.php/JSSR

Hasil perbandingan tersebut disebut dengan Angka Indeks. Angka Indeks merupakan angka perbandingan yang dinyatakan dalam persentase untuk mengukur perubahan relatif satu variabel atau lebih pada waktu tertentu atau tempat tertentu, dibandingkan dengan variabel yang sama pada waktu atau tempat yang lainnya. berasal dari software pemrograman Visual dan Access sebagai databasenya. Berikut ini adalah angka indeks pada kurs mata uang rupiah terhadap dollar. Juga perhitungan angka indeks pada harga beras dan konsumsi beras perkapita penduduk Indonesia.

\section{METODE}

Untuk membuat aplikasi perhitungan Angka Indeks ini mengambil data Kurs Dollar terhadap Rupiah dan data konsumsi beras perkapita dan ratarata harga beras wilayah Indonesia, yang bersumber dari website bps.go.id. Adapun jenis data yang diambil adalah data kuantitatif.

\section{HASIL DAN PEMBAHASAN}

Tampilan layout aplikasi dapat dilihat pada gambar berikut ini.

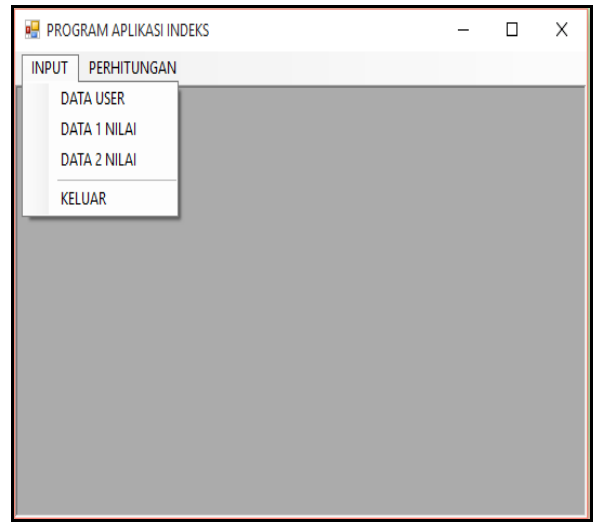

Pada tampilan menu Utama terdapat

1. Menu INPUT, digunakan untuk Input Data (Data User, Data 1 Nilai, Data 2 Nilai)

2. Menu PERHITUNGAN, digunakan untuk menampilkan proses perhitungan Angka Indeks 1 Nilai dan Angka Indeks 2 Nilai

Tampilan Form Login berikut ini digunakan untuk Login user sebelum menggunakan aplikasi dengan menginputkan username dan password.

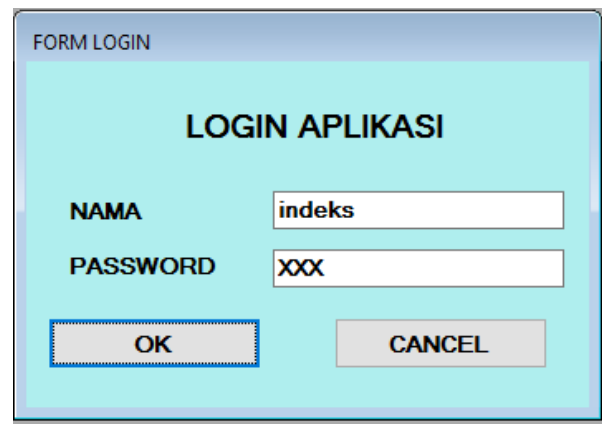

Tampilan layout penginputan untuk 1 (satu) nilai dapat dilihat pada gambar berikut
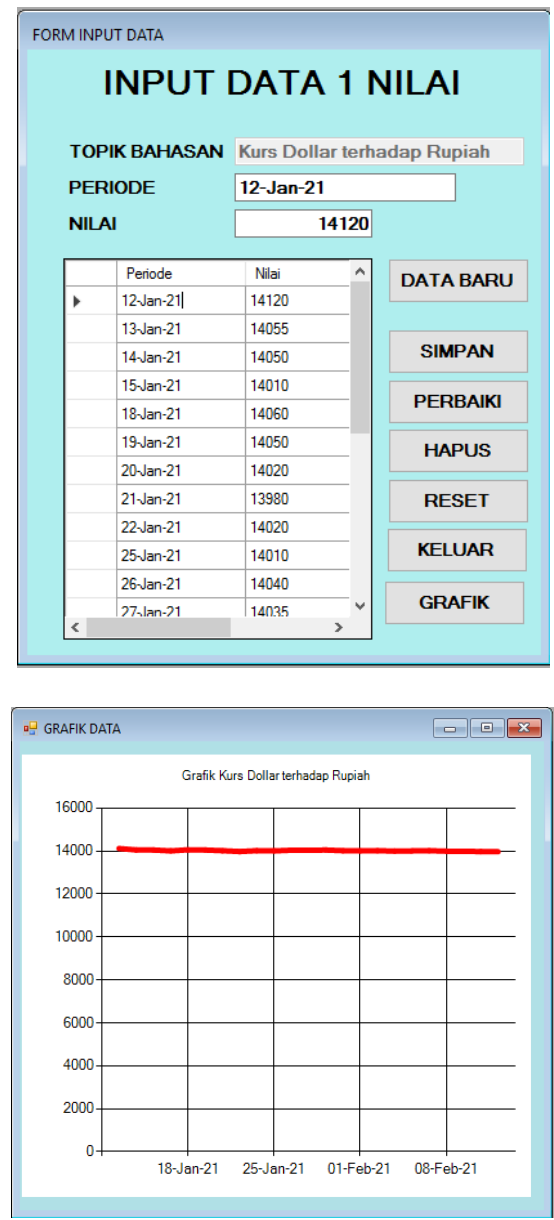
Available online at http://jurnal.goretanpena.com/index.php/JSSR

Tampilan layout form input 2 nilai

\begin{tabular}{|l|l|l|}
\hline \multicolumn{1}{|l|}{ FORM INPUT DATA } \\
INPUT
\end{tabular}

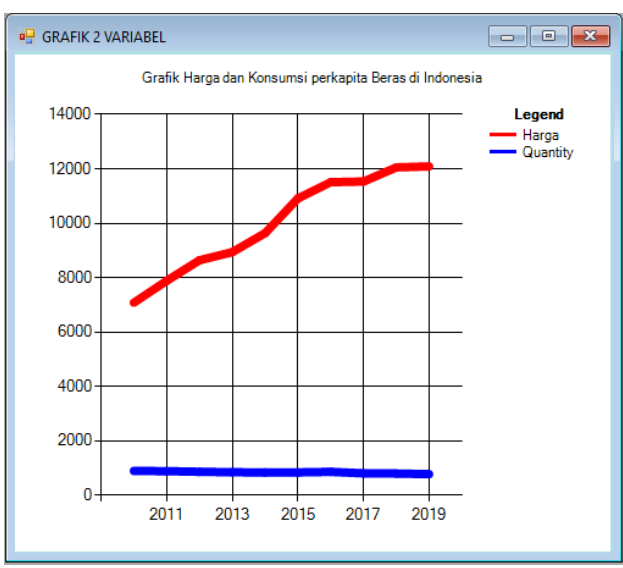

Untuk form Input Data terdapat tombol. Masing-masing tombol berfungsi sebagai berikut

1. Data Baru digunakan untuk mendefinisi-kan Topik Bahasan Data yang diinput

2. Simpan digunakan untuk menyimpan record

3. Perbaiki digunakan untuk memperbaiki record yang di input

4. Hapus digunakan untuk menghapus record

5. Reset digunakan untuk membersihkan tempat pengisian data

6. Keluar digunakan untuk menutup form
7. Grafik digunakan untuk menampilkan grafik

\section{Tampilan Form Proses Perhitungan} Angka Indeks (1 Nilai)

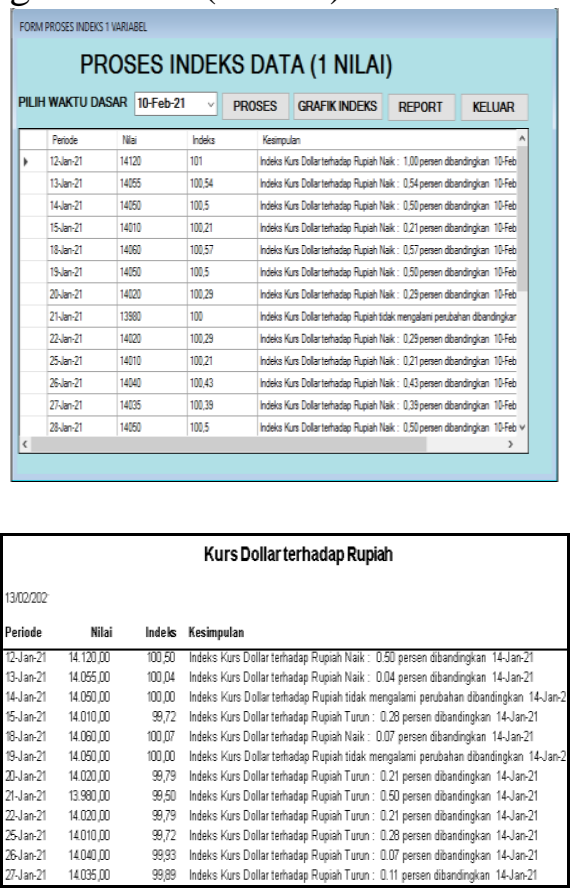

Tampilan Form Proses Perhitungan Angka Indeks (2 Nilai)

\begin{tabular}{|c|c|c|c|c|c|c|c|c|}
\hline \multicolumn{9}{|c|}{ Fomprosseshnders } \\
\hline \multicolumn{9}{|c|}{ PROSES INDEKS DATA (2 NILAI) } \\
\hline \multicolumn{3}{|c|}{ PILH WAKTU DASAR 2018} & \multicolumn{2}{|c|}{$\checkmark$ PROSES } & \multicolumn{2}{|c|}{ GRAFII INDEKS } & \multirow{2}{*}{$\begin{array}{c}\text { REPORT } \\
\text { Indesallad }\end{array}$} & $\mathrm{KE}$ \\
\hline & Peniode & Hayga & Qusartity & & elshlaya & Indescolartly & & \\
\hline ' & 20010 & 704 & 902 & 58.7 & & 112 & 65 & \\
\hline & 2011 & 7890 & 895 & 65.4 & & 111 & 73 & \\
\hline & 2012 & 8643 & 872 & 71.7 & & 108 & $\pi$ & \\
\hline & 2013 & 844 & 855 & 74,1 & & 106 & 79 & \\
\hline & 2014 & 9338 & 245 & 79.9 & & 105 & 24 & \\
\hline & 2015 & 10915 & 29 & 90.5 & & 105 & 95 & \\
\hline & 2016 & 11511 & 858 & 95,5 & & 108 & 103 & \\
\hline & 2017 & 11535 & 816 & 95.6 & & 101 & 97 & \\
\hline & 2018 & 12264 & 807 & 100 & & 100 & 100 & \\
\hline & 2019 & 12091 & 784 & 100. & & 97 & 97 & \\
\hline$\cdot$ & & & & & & & & \\
\hline
\end{tabular}

\begin{tabular}{|c|c|c|c|c|c|}
\hline \multirow{3}{*}{$\begin{array}{l}130202022 \\
\text { Periode } \\
210\end{array}$} & \multicolumn{5}{|c|}{ Harga dan Konsumsi perkapita Beras di Indonesia } \\
\hline & \multicolumn{2}{|c|}{ 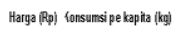 } & \multicolumn{2}{|c|}{ Indekstarga Indekcounanty } & \multirow{2}{*}{$\frac{\text { Indelekfilai }}{6500}$} \\
\hline & 700400 & 92 & 5877 & 11200 & \\
\hline 2011 & 7800000 & 805 & 65.46 & 111.0 & 7300 \\
\hline 2012 & 8663300 & 672 & 71.00 & 10800 & $\pi 00$ \\
\hline 2013 & 8941,00 & 465 & 7417 & 106000 & 7900 \\
\hline 2014 & 968,00 & 846 & 796 & 10600 & 2400 \\
\hline 2015 & 10991500 & 89 & 9055 & 10600 & 5000 \\
\hline 216 & 11511,00 & ๓8 & 5.50 & 10800 & 103000 \\
\hline 2017 & 1155,0 & 816 & 5669 & 101.00 & 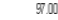 \\
\hline 2018 & 12054,100 & 977 & 10000 & 10000 & 100000 \\
\hline 2019 & 12091,00 & 784 & 10031 & 9000 & 9700 \\
\hline
\end{tabular}


Available online at http://jurnal.goretanpena.com/index.php/JSSR

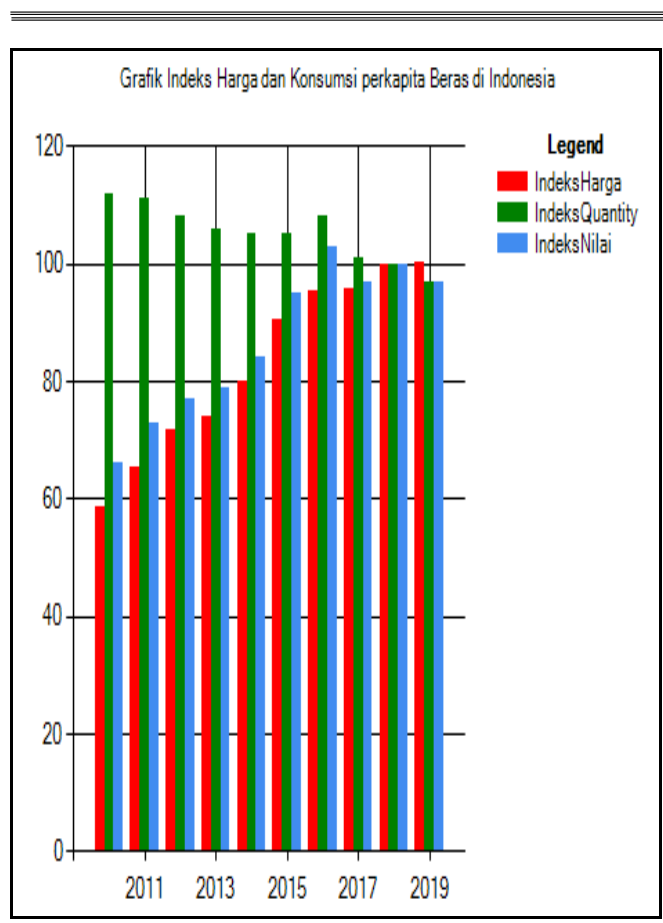

Untuk form Proses Indeks terdapat tombol dan objek. Masing-masing tombol dan objek berfungsi sebagai berikut

1. ComboBox digunakan untuk memilih waktu dasar

2. Proses digunakan untuk melakukan proses perhitungan Angka Indeks

3. Grafik digunakan untuk menampilkan grafik

4. Report digunakan untuk menampilkan laporan

5. Keluar digunakan untuk menutup form

\section{Maintenance Aplikasi}

Aplikasi yang dibangun digunakan untuk menghitung Angka Indeks Relatif, dijalankan melalui sistem operasi Windows. Aplikasi yang dibangun agar tidak mengalami kerusakan perlu di maintenance. Adapun maintenance yang dilakukan adalah maintenance pada programnya dan ataupun databasenya. Hal ini menjaga agar tidak terjadi kegagalan saat di jalankan aplikasi tersebut.

\section{SIMPULAN}

Kesimpulan yang diperoleh dari penelitian ini adalah:

1. Untuk membuat aplikasi perhitungan Angka Indeks dengan tampilan yang dirancang sendiri dapat menggunakan Visual Basic dengan database Microsoft Access.

2. Fasilitas aplikasi yang dibangun dalam menghitung Indeks Kurs Rupiah terhadap dollar, dan juga menghitung Angka Indeks Harga beras Indonesia, Konsumsi beras perkapita masyarakat Indonesia dan Indeks Nilai beras yang dilengkapi grafik serta laporan data.

\section{DAFTAR PUSTAKA}

Hasan, Iqbal. 2010. Pokok-Pokok Materi Statistik 2 (Statistik Infrensial). Jakarta: Bumi Aksara.

Tiro, Arif. 2010. Analisis Kolerasi dan Regresi. Makassar: Andira Publisher

Muhammad Sadeli (2012), Aplikasi Penjualan dengan Visual Basic 2010, Penerbit Maxikom, Palembang.

Wahana Komputer (2009), Membangun Aplikasi Toko dengan Visual Basic 2008, Penerbit Andi, Yogyakarta.

Wahana Komputer (2013), Visual Basic 2012 Programming, Penerbit Andi, Yogyakarta.

Wahana Komputer (2010), Microsoft Visual Basic 2010 \& MySQL, Penerbit Andi, Yogyakarta.

Suwanda. (2011). Desain Eksperimen untuk Penelitian Ilmiah. Bandung: Alfabeta

http://aplikasi2.pertanian.go.id/konsumsi 2017/konsumsi/kapita_per_tahun

http://epublikasi.setjen.pertanian.go.id/ar sip-buletin/53-buletinkonsumsi/620-buletin-konsumsivol-10-no-1-2019

https://www.rumusstatistik.com/2020/11/ angka-indeks.html 
Available online at http://jurnal.goretanpena.com/index.php/JSSR

https://www.indonesiainvestments.com/i $\mathrm{d} /$ bisnis/komoditas/beras/item183?

https://cpssoft.com/blog/akuntansi/penge rtian-kurs-jenis-dan-faktor https://www.ensikloblogia.com/2017/12/ pengertian-angka-indeks-macammacam.html 